\title{
DESEMPENHO AGRONÔMICO DE VARIEDADES COMERCIAIS E CRIOULAS DE MILHO EM SISTEMA ORGÂNICO
}

\author{
Otavio Duarte Giunti ${ }^{1}$, Anastácia Fontanetti ${ }^{2}$, Ariana Vieira Silva ${ }^{3}$, Carolina de Lima Tejada \\ Podestá $^{4}$, Emmanuelly Maria de Souza Fernandes ${ }^{5}$ \\ 1 Professor colaborador do IFSULDEMINAS - Campus Muzambinho, Muzambinho (MG). Email: \\ otavio.ifsuldeminas@gmail.com \\ ${ }^{2}$ Professora Associada do Departamento de Desenvolvimento Rural, Centro de Ciências Agrárias - Universidade \\ Federal de São Carlos, Araras (SP). \\ ${ }^{3}$ Professora Dra. do IFSULDEMINAS - Campus Muzambinho, Muzambinho (MG). \\ ${ }^{4}$ Graduanda em Engenharia Agronômica no IFSULDEMINAS - Campus Muzambinho, Muzambinho (MG). \\ ${ }^{5}$ Graduanda em Agroecologia. Centro de Ciências Agrárias - Universidade Federal de São Carlos, Araras (SP).
}

RESUMO: A redução no número de variedades comerciais disponíveis, a partir da liberação de cultivares transgênicas de milho, compromete a autonomia e a consolidação de sistemas orgânicos de produção. Objetivou-se avaliar, em duas localidades com altitudes distintas, características agronômicas e componentes de produção de cinco variedades comerciais (AL Avaré, AL Bandeirante, Cativerde 02, AL Piratininga e UFVM 200 - Soberano) e duas variedades crioulas (Santa Rita 1 e Santa Rita 2), em sistema orgânico de produção. O experimento foi conduzido em esquema fatorial $2 \times 7$, sendo o primeiro fator dois locais com altitudes distintas (Muzambinho/MG, $1100 \mathrm{~m}$ de altitude e Araras/SP, $665 \mathrm{~m}$ de altitude) e o segundo fator composto por sete variedades de milho, em delineamento de blocos casualizados, com quatro repetições. Avaliou-se diâmetro de colmo, altura de plantas, altura de inserção e número de folhas acima da espiga superior, índice de clorofila total Falker, teor de nitrogênio foliar, número de fileiras por espiga, de grãos por fileira e de grãos por espiga, acamamento, estande final, peso de 1000 grãos e produtividade. O ambiente, principalmente os efeitos da altitude, temperatura média noturna e diurna e a distribuição da precipitação pluviométrica, mostrou-se o fator mais importante para o rendimento de grãos de milho. $\mathrm{O}$ comportamento agronômico de todas as variedades foi superior em Muzambinho. A variedade AL Piratininga apresentou adequado desempenho agronômico tanto em alta quanto em baixa altitude e, em ambos os locais, as variedades crioulas apresentaram desempenho semelhante ao das convencionais.

Palavras-chave: Zea mays L. Caracteres agronômicos. Altitude. Precipitação pluviométrica.

\section{AGRONOMIC PERFORMANCE OF COMMERCIAL VARIETIES AND MAIZE LANDRACES IN ORGANIC SYSTEM}

\begin{abstract}
The reduction in the number of commercial varieties available, from the release of transgenic maize varieties, can compromise the autonomy and consolidation of organic production systems. The objective was to evaluate in two locations with different altitudes the agronomic performance and yield components of five commercial varieties (AL
\end{abstract} Cultura Agronômica, Ilha Solteira, v.26, n.3, p.417-432, 2017 
Avaré, AL Bandeirante, Cativerde 02, AL Piratininga and UFVM 200 - Soberano) and two maize landraces (Santa Rita 1 and Santa Rita 2) in organic system. The experiment was carried out in a $2 \times 7$ factorial, with the first factor two sites with different altitudes (Muzambinho/MG, $1100 \mathrm{~m}$ altitude e Araras/SP, $665 \mathrm{~m}$ altitude) and the second factor consisted seven corn varieties, in a randomized block with four replications. Evaluated parameters of growth and production of maize varieties. The environment, particularly the effect of altitude, average nighttime and daytime temperature and distribution of rainfall proved to be the most important factor in the yield of maize. The agronomic performance of all varieties was higher in Muzambinho. The variety AL Piratininga showed high agronomic performance in both conditions of altitude and in both locations, landraces showed agronomic performance similar to that of commercial varieties.

Key words: Zea mays L. Agronomic characteristics. Height. Rainfall.

\section{INTRODUÇÃO}

Com a liberação das cultivares transgênicas em 2008 pelo Governo Federal, houve uma redução na oferta de genótipos de milho convencionais (CRUZ et al., 2014). As variedades, apesar de manifestarem, em média, menor potencial de produção que a maioria dos híbridos, apresentam-se como alternativa viável para agricultores que utilizam menores quantidades de insumos e para regiões ou épocas de plantio com limitações para altas produtividades (GUIMARÃES et al., 2009).

A capacidade de rendimento dos grãos de milho está associada, principalmente, à eficiência metabólica, interceptação da radiação solar pelo dossel, eficiência na translocação de fotoassimilados e capacidade de dreno, sendo a intensidade luminosa, a precipitação e temperatura as variáveis com maior influência na produção de grãos e matéria seca pela cultura (BRACHTVOGEL et al., 2009; FORSTHOFER et al., 2006; MAGALHÃES; SOUZA, 2011).

A quantidade de radiação incidente depende da localização geográfica, da latitude e altitude, que tem efeito direto na variação da temperatura diurna e noturna. O milho semeado em maiores altitudes apresenta maior número de dias para atingir o pendoamento, aumentando o ciclo. Com isso, há maior período para o enchimento de grãos, refletindo no aumento do rendimento de grãos e, consequentemente, no aumento da produtividade da cultura. Porém, com condições adequadas de manejo e escolha correta da cultivar, o milho semeado em baixas altitudes pode também apresentar elevado rendimento de grãos e de matéria seca (ARGENTA et al., 2003).

A determinação do potencial de produção de grãos de milho em sistema orgânico e em distintas altitudes é fundamental para a recomendação adequada das variedades a serem utilizadas. Assim, objetivou-se avaliar em duas localidades com altitudes distintas, as 
características agronômicas e os componentes de produção de sete variedades de milho, em sistema orgânico de produção.

\section{MATERIAL E MÉTODOS}

No ano agrícola 2014/2015 foram instaladas duas unidades experimentais, em altitudes distintas: a unidade 1 foi conduzida em área experimental do Centro de Ciências Agrárias (CCA), da Universidade Federal de São Carlos - UFSCar, Campus Araras (SP), em Latossolo Vermelho distrófico (EMBRAPA, 2013), situada a $665 \mathrm{~m}$ de altitude (latitude 22¹8'27,75', Sul e longitude 47²3'09,83'' Oeste, clima Cwa, segundo Köppen (1948). A área está em manejo orgânico há aproximadamente seis anos. A unidade experimental 2 foi instalada no Instituto Federal de Educação, Ciência e Tecnologia do Sul de Minas Gerais IFSULDEMINAS, Campus Muzambinho, em Latossolo Vermelho-Amarelo distrófico (EMBRAPA, 2013), situada a $1100 \mathrm{~m}$ de altitude (latitude 2122'33'' Sul e longitude 46³1'32'" Oeste), clima Cwb, segundo Köppen (1948). A área não foi cultivada anteriormente em manejo orgânico, mas estava em pousio nas três safras anteriores (2011/12, 2012/13 e 2013/14). As informações referentes à altitude e coordenadas geográficas das unidades experimentais foram obtidas junto às Estações Meteorológicas Automáticas da UFSCar, Campus Araras e do IFSULDEMINAS, Campus Muzambinho.

O delineamento experimental utilizado foi o de blocos casualizados, em esquema fatorial 2x7, sendo dois locais (Araras e Muzambinho) e sete variedades (cinco variedades comerciais: AL Avaré, AL Bandeirante, AL Piratininga, Cativerde 02 e UFVM 200 Soberano e duas variedades crioulas, denominadas Santa Rita 1 e Santa Rita 2), com quatro repetições, totalizando 28 parcelas em cada local.

As variedades crioulas foram selecionadas em um banco particular de sementes e cedidas por um produtor do município de Santa Rita de Caldas/MG. É uma propriedade pequena, caracterizada como familiar e localizada a $1080 \mathrm{~m}$ de altitude, enquadrando-se no clima tipo Cwb, segundo Köppen (1948). Essas variedades, por não serem comerciais, não passaram por avaliações de produtividade ou de condições adequadas para seu desenvolvimento; são cultivadas há gerações pela família do produtor e utilizadas para consumo humano e animal na própria propriedade e armazenadas para plantio na safra seguinte.

A parcela experimental foi constituída de oito linhas com 5,0 m de comprimento, espaçadas em $0,8 \mathrm{~m}$, com cinco plantas por metro e densidade populacional de plantio de 62.500 plantas ha ${ }^{-1}$. A área total de cada parcela foi de $32 \mathrm{~m}^{2}$, com avaliação das duas linhas centrais de cada parcela, excluindo $0,5 \mathrm{~m}$ de cada extremidade das linhas, totalizando área útil de avaliação de $6,4 \mathrm{~m}^{2}$.

Inicialmente foram coletadas amostras de solos na profundidade de 0-0,20 m, para caracterização química do solo. Para as análises, seguiu-se a metodologia proposta pelo

Cultura Agronômica, Ilha Solteira, v.26, n.3, p.417-432, 2017 
manual da Embrapa (CLAESSEN, 1997). Os resultados das análises de solo das áreas experimentais encontram-se na Tabela 1.

Tabela 1. Atributos químicos do solo, na profundidade de $0-0,20 \mathrm{~m}$, antes da semeadura do experimento. Muzambinho/MG e Araras/SP, ano agrícola 2014/2015.

\begin{tabular}{lcccccccccc}
\hline Amostra & $\begin{array}{c}\text { P resina } \\
\left(\mathrm{mg} / \mathrm{dm}^{3}\right)\end{array}$ & $\begin{array}{c}\text { M.O. } \\
\left(\mathrm{g} / \mathrm{dm}^{3}\right)\end{array}$ & $\begin{array}{c}\mathrm{pH} \\
\left(\mathrm{CaCl}_{2}\right)\end{array}$ & $\begin{array}{c}\mathrm{K} \\
---\mathrm{Ca}^{2}\end{array}$ & $\mathrm{Ca}$ & $\mathrm{Mg}$ & $\mathrm{H}+\mathrm{Al}$ & $\mathrm{SB}$ & $\mathrm{CTC}$ & $\mathrm{V}$ \\
$\mathrm{MZ}$ & 45 & 33 & 5,4 & 6,2 & 28 & 10 & 33 & 44,1 & 77,1 & 57 \\
$\mathrm{AR}$ & 9 & 19 & 5,6 & 3,4 & 23 & 9 & 27 & 35 & 61,5 & 57 \\
\hline
\end{tabular}

MZ - Muzambinho; AR - Araras.

Para a adubação utilizou-se, nas duas localidades, $10,0 \mathrm{Mg} \mathrm{ha}^{-1}$, em peso seco e com respectiva correção de umidade, do composto Visafértil Orgânico®, contendo $13 \mathrm{~kg} \mathrm{Mg}^{-1} \mathrm{de}$ $\mathrm{N} ; 31,3 \mathrm{~kg} \mathrm{Mg}^{-1}$ de $\mathrm{P}_{2} \mathrm{O}_{5}$; 16,2 $\mathrm{kg} \mathrm{Mg}^{-1} \mathrm{de} \mathrm{K}_{2} \mathrm{O} ; 111,1 \mathrm{~kg} \mathrm{Mg}^{-1} \mathrm{de} \mathrm{CaO} ; 9,8 \mathrm{~kg} \mathrm{Mg}^{-1} \mathrm{de} \mathrm{MgO}$; $15,0 \mathrm{~kg} \mathrm{Mg}^{-1}$ de $\mathrm{SO}_{4} ; 0,0692 \mathrm{~kg} \mathrm{Mg}^{-1} \mathrm{de} \mathrm{Cu} ; 0,561 \mathrm{~kg} \mathrm{Mg}^{-1} \mathrm{de}$ Fe; 0,511 kg Mg-1 de Mn; 0,766 $\mathrm{kg} \mathrm{Mg}^{-1} \mathrm{de} \mathrm{Zn} ; 37,40 \%$ de umidade e $\mathrm{pH}$ de 8,0. A dosagem utilizada seguiu a recomendação de Coelho (2006), visando suprir a dose de $0,130 \mathrm{Mg}^{-1}$ de nitrogênio, para uma produtividade esperada de grãos de 6 a $8 \mathrm{Mg} \mathrm{ha}^{-1}$. A dose total do composto foi aplicada uma única vez, distribuída na linha de semeadura, por ocasião do plantio.

O preparo do solo em pré-plantio foi feito mediante uma operação de aração e duas de gradagens. A semeadura foi realizada no dia 04/12/2014 em Muzambinho e no dia 17/12/2014 em Araras. Aos 25 dias após a emergência (DAE), foi realizado o desbaste, em ambas as cidades, nas parcelas, para o estabelecimento da população de 55.000 plantas de milho por hectare.

As sementes das variedades comerciais e crioulas não receberam tratamento de inseticida e fungicida. O controle das plantas espontâneas foi realizado por meio de três capinas manuais e, para o controle da lagarta do cartucho (Spodoptera frugiperda J. E. Smith, 1797), foi realizada uma aplicação do inseticida biológico Dipel $\mathrm{WP}^{\circledR}$ (Bacillus thuringiensis var. kurstaki) na dose de $500 \mathrm{~g} \mathrm{ha}^{-1}$ (16,80 $\mathrm{g} \mathrm{ha}^{-1}$ de ingrediente ativo), no estádio fenológico V6 (seis folhas expandidas).

Para coleta de dados foram marcadas, ao acaso, 10 plantas na área útil de cada parcela e, no estádio fenológico R1 (florescimento) avaliou-se: a) diâmetro médio de colmo, em milímetros, medido na metade do primeiro entrenó expandido; b) altura média das plantas, em centímetros, medindo-se do nível do solo à base da inserção da folha bandeira; c) a altura média de inserção da espiga superior, em centímetros, medindo-se do nível do solo até a inserção da espiga superior; d) o número médio de folhas acima da espiga superior; e) índice de clorofila Falker (ICF) total, utilizando-se o aparelho ClorofiLOG (FALKER, 2008), com leituras no terço inferior, médio e superior da folha inteira, oposta e abaixo da espiga superior de cada planta e, f) determinação do teor de nitrogênio foliar (N) em laboratório. Para a determinação do teor de $\mathrm{N}$ foliar, seguiu-se a metodologia proposta por Malavolta et al. (1997), com a coleta da folha oposta e abaixo da espiga superior, sendo amostradas 10 folhas

Cultura Agronômica, Ilha Solteira, v.26, n.3, p.417-432, 2017 
por parcela, posteriormente secas em estufa, moídas em moinho tipo Willey e encaminhadas para a análise química em laboratório.

Todas as espigas das duas linhas centrais das parcelas foram colhidas no estádio R6 (maturidade fisiológica), quando os grãos apresentaram aproximadamente 18 a $21 \%$ de umidade e avaliaram-se: a) número médio de plantas acamadas, computadas aquelas que apresentaram tombamento natural, com resultados expressos em porcentagem; b) número médio de fileiras por espiga; c) número médio de grãos por fileira; d) número médio de grãos por espiga; todas as avaliações realizadas em dez espigas por parcela; e) estande final, expresso em plantas parcela $^{-1}$; f) massa de 1000 grãos, obtida do total de grãos oriundos da debulha de todas as espigas das duas linhas centrais da parcela útil, com retirada de quatro amostras ao acaso, as quais foram submetidas à pesagem, além da determinação imediata de umidade e; h) produtividade, expressa em $\mathrm{kg}_{\text {parcela }}{ }^{-1}$. Os valores do estande final foram convertidos em plantas ha ${ }^{-1}$, assim como os valores da produtividade foram convertidos em $\mathrm{kg} \mathrm{ha}^{-1}$. Para a determinação da massa de 1000 grãos e da produtividade, houve correção para $13 \%$ de umidade.

Tabela 2. Radiação total incidente, soma térmica e radiação incidente por unidade de tempo térmico, para estádios compreendidos entre a emergência e oito folhas expandidas (Ve a V8) e V8 e o florescimento feminino (R1). Araras/SP e Muzambinho/MG, ano agrícola 2014/15.

\begin{tabular}{lcccccc}
\hline \multirow{2}{*}{$\begin{array}{c}\text { Estádio de } \\
\text { desenvolvimento }\end{array}$} & \multicolumn{2}{c}{$\begin{array}{c}\text { Radiação solar } \\
\left(\mathrm{cal} \mathrm{cm}^{-2} \mathrm{dia}^{-1}\right)\end{array}$} & \multicolumn{2}{c}{$\begin{array}{c}\text { Soma térmica } \\
\left({ }^{\circ} \mathrm{C} \mathrm{dia}^{-1}\right)\end{array}$} & \multicolumn{2}{c}{$\begin{array}{c}\text { Radiação solar } \\
(\text { unidade de tempo }\end{array}$} \\
\cline { 2 - 7 } & $\mathrm{AR}$ & $\mathrm{MZ}$ & $\mathrm{AR}$ & $\mathrm{MZ}$ & $\mathrm{AR}$ & $\mathrm{MZ}$ \\
\hline Ve a V8 & 515,42 & 498,05 & 15,92 & 12,95 & 32,37 & 38,46 \\
V8 a R1 & 541,74 & 494,51 & 14,74 & 12,12 & 36,75 & 40,80 \\
\hline
\end{tabular}

AR - Araras. Fonte: Estação automática da Universidade Federal de São Carlos (UFSCar), Campus Araras; MZ - Muzambinho. Fonte: Estação meteorológica automática do IFSULDEMINAS, Campus Muzambinho.

Tabela 3. Temperatura média diária, temperatura média noturna e precipitação pluviométrica nos estádios compreendidos entre o plantio e quatro folhas expandidas (V4), V4 e oito folhas expandidas (V8), V8 e o florescimento feminino (R1), R1 e a colheita dos grãos de milho (R6). Araras/SP e Muzambinho/MG, ano agrícola 2014/15.

\begin{tabular}{lcccccc}
\hline \multirow{2}{*}{$\begin{array}{c}\text { Estádio de } \\
\text { desenvolvimento }\end{array}$} & \multicolumn{2}{c}{$\begin{array}{c}\text { Temperatura média } 24 \\
\text { horas }\left({ }^{\circ} \mathrm{C}\right)\end{array}$} & \multicolumn{2}{c}{$\begin{array}{c}\text { Temperatura média } \\
\text { noturna }\left({ }^{\circ} \mathrm{C}\right)\end{array}$} & \multicolumn{2}{c}{$\begin{array}{c}\text { Precipitação } \\
(\mathrm{mm})\end{array}$} \\
\cline { 2 - 7 } & $\mathrm{AR}$ & $\mathrm{MZ}$ & $\mathrm{AR}$ & $\mathrm{MZ}$ & $\mathrm{AR}$ & $\mathrm{MZ}$ \\
\hline Plantio a V4 & 24,68 & 20,50 & 22,86 & 19,67 & 167,20 & 344,00 \\
V4 a V8 & 24,78 & 22,73 & 23,13 & 22,12 & 174,30 & 190,20 \\
V8 a R1 & 23,74 & 20,84 & 21,67 & 20,78 & 163,10 & 256,60 \\
R1 a R6 & 20,21 & 18,29 & 19,16 & 16,69 & 344,30 & 392,40 \\
Total & - & - & - & - & 849,90 & 1183,2 \\
\hline
\end{tabular}

AR - Araras. Fonte: Estação automática da Universidade Federal de São Carlos (UFSCar), Campus Araras; MZ - Muzambinho. Fonte: Estação meteorológica automática do IFSULDEMINAS, Campus Muzambinho.

Cultura Agronômica, Ilha Solteira, v.26, n.3, p.417-432, 2017 
Os dados meteorológicos referentes à precipitação pluvial, temperatura do ar (máxima, média, mínima e temperatura média noturna) e radiação solar foram obtidos nas Estações Meteorológicas Automáticas da UFSCar, Campus Araras (SP) e do IFSULDEMINAS, Campus Muzambinho (MG), com o cálculo da soma térmica levando em consideração a temperatura basal da cultura em $10^{\circ} \mathrm{C}$ (Tabelas 2 e 3 ). A partir desses dados foi elaborado o balanço hídrico mensal para as duas localidades (Figuras 1 e 2), seguindo a metodologia proposta por Rolim et al. (1998).

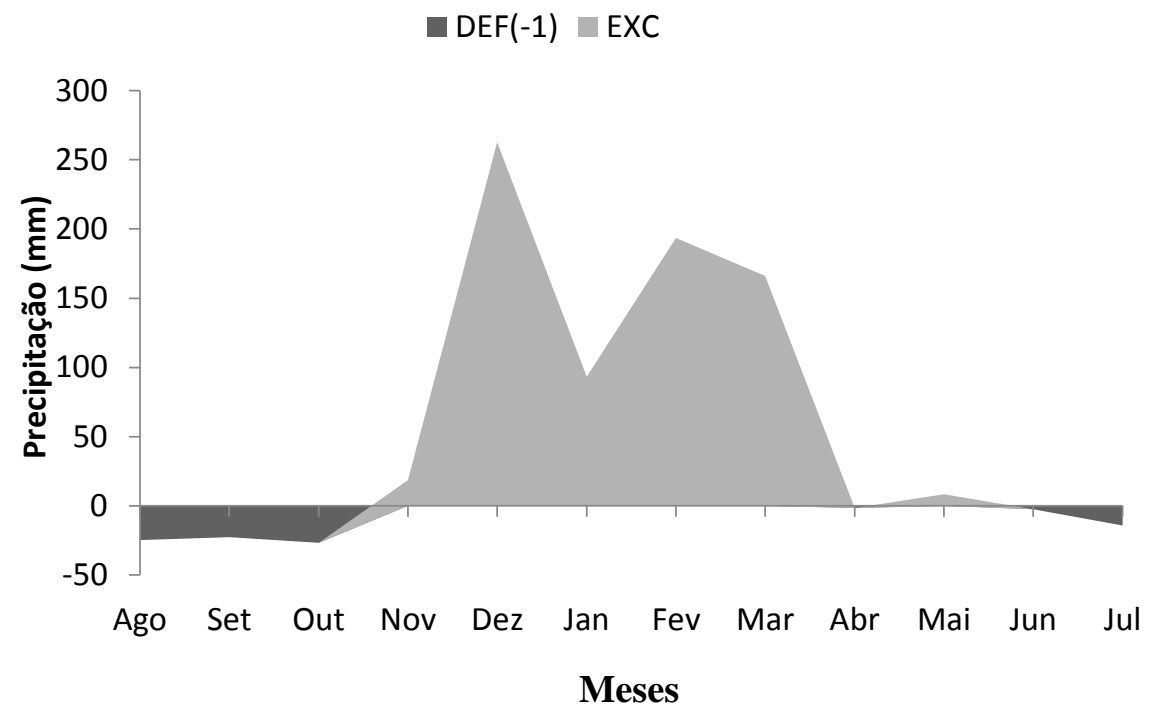

Figura 1. Balanço hídrico mensal, Muzambinho (MG), no período de agosto de 2014 a julho de 2015.

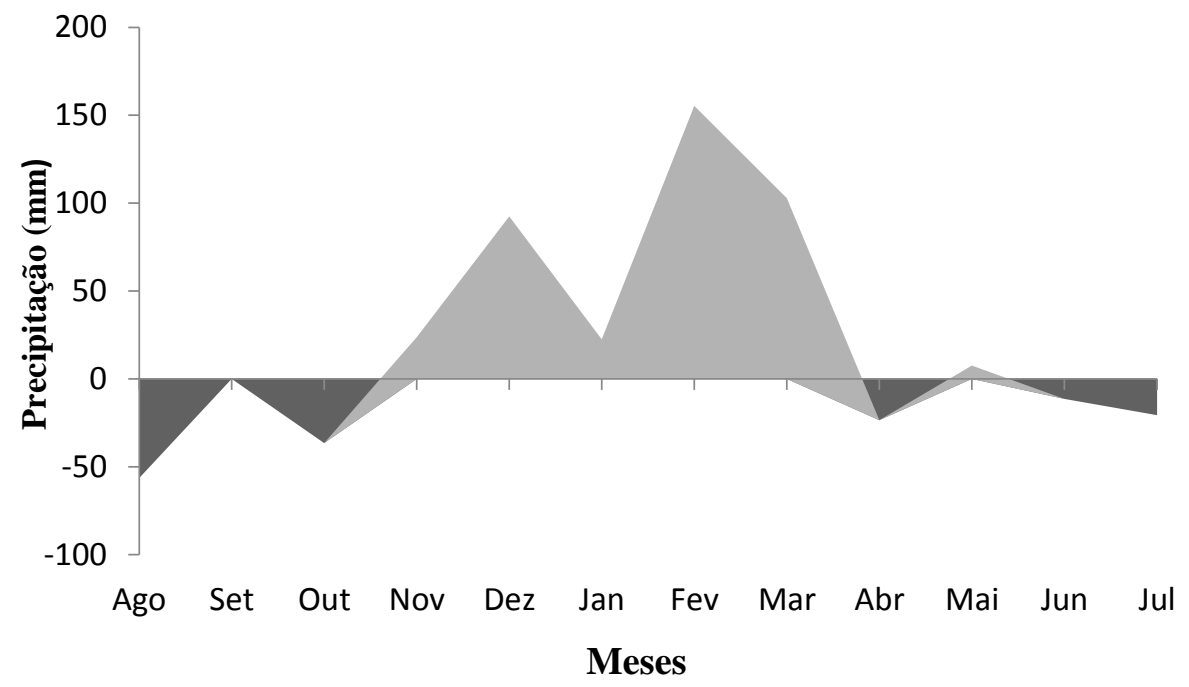

Figura 2. Balanço hídrico mensal, Araras (SP), no período de agosto de 2014 a julho de 2015. 
Os dados obtidos foram submetidos à análise de variância e as médias comparadas pelo teste de Tukey (5\%) no programa estatístico SISVAR (FERREIRA, 2011).

\section{RESULTADOS E DISCUSSÃO}

Para as variáveis número de folhas acima da espiga superior (NFAES), número de grãos por espiga (NGE) e produtividade de grãos (PROD) houve efeito da interação entre os fatores local e variedades, com menores valores para os parâmetros NFAES, NGE e PROD verificados no município de Araras, para todas as variedades, exceto para o parâmetro NFAES para a variedade Santa Rita 2 (Tabelas 4 e 5).

Tabela 4. Valores médios do número de folhas acima da espiga superior (NFAES) e número de grãos por espiga (NGE) de variedades de milho em função da interação local de plantio $\mathrm{x}$ variedades. Araras/SP e Muzambinho/MG, ano agrícola 2014/15.

\begin{tabular}{lllll}
\hline \multicolumn{1}{c}{ Variedade } & AR & MZ & \multicolumn{1}{c}{ AR } & MZ \\
\hline \multicolumn{2}{c}{ NFAES } & \multicolumn{2}{c}{ NGE } \\
\hline AL Avaré & $5,83 \mathrm{Ba}$ & $6,80 \mathrm{Aa}$ & $473,75 \mathrm{Ba}$ & $545,50 \mathrm{Aab}$ \\
AL Bandeirante & $5,60 \mathrm{Bab}$ & $6,53 \mathrm{Aa}$ & $426,75 \mathrm{Bab}$ & $577,18 \mathrm{Aa}$ \\
Cativerde 02 & $4,98 \mathrm{Bb}$ & $6,53 \mathrm{Aa}$ & $465,30 \mathrm{Ba}$ & $534,95 \mathrm{Aab}$ \\
AL Piratininga & $5,82 \mathrm{Ba}$ & $6,40 \mathrm{Aa}$ & $440,80 \mathrm{Bab}$ & $599,40 \mathrm{Aa}$ \\
Santa Rita 1 & $5,73 \mathrm{Bab}$ & $6,45 \mathrm{Aa}$ & $404,30 \mathrm{Bab}$ & $557,00 \mathrm{Aab}$ \\
Santa Rita 2 & $6,10 \mathrm{Aa}$ & $6,28 \mathrm{Aa}$ & $375,30 \mathrm{Bb}$ & $474,98 \mathrm{Ab}$ \\
UFVM 200 - Soberano & $5,73 \mathrm{Bab}$ & $6,48 \mathrm{Aa}$ & $438,10 \mathrm{Bab}$ & $514,58 \mathrm{Aab}$ \\
\hline
\end{tabular}

AR - Araras; MZ - Muzambinho. Médias seguidas de letras maiúsculas iguais na linha não diferem entre si. Médias seguidas de letras minúsculas iguais na coluna não diferem entre si.

Tabela 5. Valores médios da produtividade de grãos (PROD), em kg ha-1 ${ }^{-1}$ de variedades de milho em função da interação local de plantio x variedades. Araras/SP e Muzambinho/MG, ano agrícola 2014/15.

\begin{tabular}{lcc}
\hline \multirow{2}{*}{ Variedade } & \multicolumn{1}{c}{ AR } & MZ \\
\cline { 2 - 3 } & \multicolumn{2}{c}{ PROD $\left(\mathrm{kg} \mathrm{ha}^{-1}\right)$} \\
\hline AL Avaré & $4470,24 \mathrm{Bab}$ & $8187,26 \mathrm{Ab}$ \\
AL Bandeirante & $4212,57 \mathrm{Bab}$ & $11449,76 \mathrm{Aa}$ \\
Cativerde 02 & $4218,41 \mathrm{Bab}$ & $8020,84 \mathrm{Ab}$ \\
AL Piratininga & $6388,11 \mathrm{Ba}$ & $9876,33 \mathrm{Aab}$ \\
Santa Rita 1 & $3335,59 \mathrm{Bb}$ & $8701.94 \mathrm{Ab}$ \\
Santa Rita 2 & $4898,79 \mathrm{Bab}$ & $8724,17 \mathrm{Ab}$ \\
UFVM 200 - Soberano & $3929,95 \mathrm{Bab}$ & $8724,57 \mathrm{Ab}$
\end{tabular}

AR - Araras; MZ - Muzambinho. Médias seguidas de letras maiúsculas iguais na linha não diferem entre si. Médias seguidas de letras minúsculas iguais na coluna não diferem entre si.

Em Araras, as variedades AL Avaré, AL Piratininga e Santa Rita 2 apresentaram maior NFAES, estatisticamente semelhante às variedades AL Bandeirante, Santa Rita 1 e UFVM 200 Soberano que, por sua vez não diferiram da variedade Cativerde 02. Já em Muzambinho,

Cultura Agronômica, Ilha Solteira, v.26, n.3, p.417-432, 2017 
não houve diferença significativa entre as variedades, para esse parâmetro (Tabela 4). De acordo Costa et al. (2005), a quantidade de folhas acima da espiga é essencial para proporcionar bom rendimento da cultura, uma vez que estas são o centro da produção de carboidratos, responsáveis pela nutrição dos órgãos vegetativos e reprodutivos. No caso da variedade Cativerde 02 em Araras, mesmo com menor valor de NFAES, tal fato não reduziu o número de grãos por espiga e a produtividade, em relação às demais variedades, pois, provavelmente, mesmo estatisticamente inferior às demais variedades, o NFAES da variedade Cativerde foi suficiente para promover produção de fotoassimilados em quantidades adequadas para suprir as necessidades da planta, não impactando no enchimento de grãos e produtividade da cultura.

Em relação ao NGE, em Araras, os valores obtidos pelas variedades AL Avaré e Cativerde 02 não diferiram dos obtidos pelas variedades AL Bandeirante, AL Piratininga, Santa Rita 1 e UFVM - 200 Soberano, sendo os valores de NGE observados por essas três últimas variedades estatisticamente semelhantes ao da variedade Santa Rita 2. Em Muzambinho, as variedades AL Bandeirante e AL Piratininga apresentaram valores mais elevados, semelhantes aos das variedades AL Avaré, Cativerde 02, Santa Rita 01 e AL Piratininga, que se mostraram estatisticamente semelhantes ao da variedade Santa Rita 2 (Tabela 4).

A variedade AL Bandeirante mostrou-se a mais produtiva em Muzambinho, mas não se diferiu da variedade AL Piratininga, e esta não diferiu das demais variedades. Em Araras, a variedade AL Piratininga apresentou maior produtividade de grãos, mas semelhante às variedades AL Avaré, AL Bandeirante, Cativerde 02, Santa Rita 2 e UFVM - 200 Soberano (Tabela 5). Os valores obtidos em Muzambinho foram superiores às médias obtidas por Freitas et al. (2013), em onze ambientes na região norte/oeste de São Paulo, microrregiões de Adamantina, Barretos, Catanduva, Ituverava e Votuporanga, em sistema convencional e em baixas altitudes, para as variedades AL Avaré, AL Piratininga e AL Bandeirantes. Porém, para o município de Araras esses valores foram menores, exceto para a AL Piratininga. E, em Araras, as variedades apresentaram produtividades semelhantes às obtidas por algumas variedades testadas por Cruz et al. (2009) em sistema orgânico de produção, em Sete Lagoas (MG), superando a média obtida pela variedade AL Piratininga.

A variedade crioula Santa Rita 1 apresentou produtividade semelhante à obtida pela maioria das variedades comerciais, tanto em Muzambinho, quanto em Araras, assemelhandose aos resultados obtidos por Carpentieri-Pípolo et al. (2010), que observaram desempenho semelhante entre variedades crioulas e comerciais, em sistemas de manejo com baixo nível tecnológico. Araújo Junior et al. (2015), ao compararem o desempenho produtivo de cinco variedades de milho crioulos com o de um híbrido comercial, em manejo orgânico, no semiárido potiguar, não verificaram diferenças na produção entre as cultivares testadas.

Observando as variações de temperatura e de radiação solar incidente nos dois ambientes de plantio (Tabela 2) nota-se que, em Araras, houve maior disponibilidade de radiação solar por superfície, assim como maior número de unidades térmicas acumuladas

Cultura Agronômica, Ilha Solteira, v.26, n.3, p.417-432, 2017 
por dia, para a temperatura basal da cultura em $10^{\circ} \mathrm{C}$, nos estádios fenológicos compreendidos entre Ve e V8 e entre este último e R1. Tal situação deve-se, provavelmente, à ocorrência de temperaturas mais elevadas (diurnas e noturnas) no município de Araras (Tabela 3).

Em contrapartida, em Muzambinho foram observados valores mais elevados da radiação solar disponível por unidade de tempo térmico para os estágios compreendidos entre Ve e R1, com percentuais de diferença de $18,81 \%$ no período compreendido entre Ve e V8 e 11,02\% entre V8 e R1 (Tabela 2). Assim, a maior relação entre a radiação disponível por unidade térmica de desenvolvimento verificada no início do período de enchimento de grãos favoreceu o incremento no rendimento do milho em Muzambinho. Esses resultados assemelham-se aos obtidos por Argenta et al. (2003), ao compararem a produtividade de milho em ambientes com altitudes distintas, em Santa Catarina.

Temperaturas elevadas aumentam a respiração e o consumo energético, reduzindo a taxa de fotossíntese líquida e, consequentemente, a produção da cultura. Ao contrário, temperaturas amenas resultam em maior eficiência na conversão de radiação solar em carbono orgânico, que é melhor repartido entre os grãos, resultando em maiores potenciais de produtividade, conforme verificado por Brachtvogel et al. (2009) e Galon et al. (2010).

A precipitação pluviométrica total foi adequada para o milho nos dois locais de plantio. Porém, em Muzambinho, foi superior e melhor distribuída durante os estádios de desenvolvimento da cultura (Tabela 3). De acordo com Fancelli (2015), o milho exige entre 400 a $600 \mathrm{~mm}$ de precipitação para que alcance índices adequados de produtividade. Esses valores foram ultrapassados nos dois municípios, mas, ao se analisar o balanço hídrico de Araras (Figura 2), observa-se que no mês de abril de 2015, com a cultura no estádio de grão pastoso (R3) ocorreu deficiência hídrica (5,8 mm de precipitação). Fancelli (2015) indica que a ocorrência de restrições hídricas nesse período pode incidir em maior porcentagem de grãos leves e com menor diâmetro, comprometendo a produção da cultura, o que pode ter resultado em menor produtividade de grãos em Araras.

O local de plantio afetou significativamente a maioria das variáveis analisadas, com exceção do índice de clorofila total Falker (ICF) e porcentagem de acamamento (\% ACA). O melhor desempenho agronômico, independente das variedades de milho foi observado no município de Muzambinho (Tabela 6), principalmente por fatores climáticos, notadamente temperaturas diurnas e noturnas menores, precipitação pluviométrica melhor distribuída e condições de altitude mais elevada e por teores de $\mathrm{N}$ foliar e matéria orgânica do solo mais elevados nesse município.

O déficit hídrico ocorrido no município de Araras em abril de 2015 (Figura 2) pode ter refletido em menor número de fileiras por espiga (NFE), de grãos por fileira (NGF) e de peso de 1000 grãos (P1000) (Tabelas 5 e 6), fato que pode ter contribuído para a menor produtividade de grãos nessa localidade, uma vez que esse período coincidiu com o estádio de desenvolvimento da cultura no qual ocorre acentuada deposição de amido (R3), com reflexos no ganho de peso do grão e condições hídricas adversas podem afetar o peso e o

Cultura Agronômica, Ilha Solteira, v.26, n.3, p.417-432, 2017 
diâmetro dos grãos. Balbinot Júnior et al. (2005) observaram, através da realização de análise de trilha e Stepwise, que o parâmetro número de grãos por fileira mostrou-se o mais relevante na predição de produtividade de variedades de polinização aberta de milho.

Tabela 6. Valores médios de diâmetro de colmo (DC), altura das plantas (AP), altura de inserção de espiga superior (AIE), índice de clorofila total Falker (ICF), teor de nitrogênio foliar $(\mathrm{N})$, número de fileiras por espiga $(\mathrm{NFE})$, número de grãos por fileira (NGF), porcentagem de acamamento (ACA), estande final (EF) e peso de 1000 grãos (P1000) das plantas em função de locais de plantio. Araras/SP e Muzambinho/MG, ano agrícola 2014/15.

\begin{tabular}{lccccc}
\hline Local & DC $(\mathrm{mm})$ & AP $(\mathrm{cm})$ & AIE $(\mathrm{cm})$ & ICF & N \\
\hline AR & $23,01 \mathrm{~b}$ & $235,78 \mathrm{~b}$ & $138,78 \mathrm{~b}$ & $54,97 \mathrm{a}$ & $22,95 \mathrm{~b}$ \\
$\mathrm{MZ}$ & $32,39 \mathrm{a}$ & $316,16 \mathrm{a}$ & $200,60 \mathrm{a}$ & $55,23 \mathrm{a}$ & $27,33 \mathrm{a}$ \\
\hline & NFE & NGF & ACA $(\%)$ & EF $\left(\right.$ plantas ha $\left.{ }^{-1}\right)$ & P1000 $(\mathrm{g})$ \\
\hline AR & $12,78 \mathrm{~b}$ & $34,31 \mathrm{~b}$ & $24,64 \mathrm{a}$ & $43761,00 \mathrm{~b}$ & $322,98 \mathrm{~b}$ \\
MZ & $14,39 \mathrm{a}$ & $37,82 \mathrm{a}$ & $25,36 \mathrm{a}$ & $54441,86 \mathrm{a}$ & $339,01 \mathrm{a}$ \\
\hline
\end{tabular}

AR - Araras; MZ - Muzambinho. Médias seguidas de mesma letra na coluna não diferem entre si de acordo com o teste de Tukey $(\mathrm{p}<0,05)$.

A menor produtividade de grãos de milho em Araras deve-se também ao menor teor de nitrogênio foliar (Tabela 6) e ao teor de matéria orgânica no solo observado na área experimental nesse município (Tabela 1). Em Muzambinho, os teores de $\mathrm{N}$ foliar mostraramse superiores aos obtidos em Araras, com teor médio próximo $\left(27,33 \mathrm{~g} \mathrm{~kg}^{-1}\right)$ da faixa adequada de 27,5 a 32,5 $\mathrm{g} \mathrm{kg}^{-1}$ para a cultura no milho (MALAVOLTA et al., 1997). Já em Araras, o teor médio de $\mathrm{N}$ foliar $\left(22,95 \mathrm{~g} \mathrm{~kg}^{-1}\right)$ foi abaixo do considerado adequado. Folhas com teores adequados de $\mathrm{N}$, por assimilarem maior quantidade de $\mathrm{CO}_{2}$ e sintetizarem mais carboidratos na fotossíntese, acumulam mais biomassa seca, resultando em maior rendimento de grãos (KAPPES et al., 2009; NASCIMENTO et al., 2012).

Já em relação ao teor de matéria orgânica no solo, em Muzambinho este foi de $33 \mathrm{~g} \mathrm{dm}^{-}$ 3 , enquanto que, em Araras apresentou-se em $19 \mathrm{~g} \mathrm{dm}^{-3}$ (Tabela 1), o que pode ter influenciado menores produtividades neste município uma vez que é estimada para cada $1 \%$ de matéria orgânica do solo, uma disponibilidade de $20 \mathrm{~kg} \mathrm{ha}^{-1}$ de N (COELHO et al., 2010).

O menor estande final de plantas (EF) observado em Araras (Tabela 6) soma-se aos fatores anteriores que podem ter influenciado a menor produtividade de grãos de milho nesse município.

Para as variáveis altura de plantas (AP), altura de inserção de espiga superior (AIE), índice de clorofila total Falker (ICF), número de fileiras por espigas (NFE), porcentagem de acamamento (\% ACA) e peso de 1000 grãos (P1000), observou-se efeito isolado das variedades.

Os menores valores de AP foram verificados para as variedades AL Avaré, AL Piratininga, AL Bandeirantes, AL Piratininga, UFVM - 200 Soberano e Cativerde 02 (Tabela 7). Em relação à AIE, as variedades AL Avaré, UFVM - 200 Soberano e AL Bandeirante 
apresentaram menores valores e semelhantes entre si, enquanto a variedades AL Piratininga e Cativerde 02 foram estatisticamente iguais, superiores à variedade AL Bandeirante e semelhante à variedade UFVM - 200 Soberano. Já as variedades Santa Rita 1 e Santa Rita 2 apresentaram a maior AP e AIE (Tabela 7). Freitas et al. (2013) ao avaliarem o desempenho de cultivares de milho nas regiões norte e oeste do estado de São Paulo, em condições de baixa altitude, obtiveram, como média de 11 experimentos, valores mais baixos para os parâmetros altura de plantas e de inserção da espiga superior para as variedades AL Bandeirante, AL Avaré e AL Piratininga. E Santos et al. (2015), ao avaliarem cultivares de milho em Andradina (SP), com altitude de 379 m, obtiveram, para a variedade Cativerde 02, valores próximos aos obtidos nesse estudo, no manejo convencional, mas inferiores quando no manejo orgânico. Valores elevados de altura de plantas e inserção de espigas são característicos em variedades crioulas de milho e os resultados assemelham-se aos obtidos por Araujo et al. (2013), Fonseca et al. (2015) e Silveira et al. (2015). Por sua vez, Araújo Júnior et al (2015) não observaram diferenças, para esses parâmetros, ao compararem variedades crioulas com um híbrido comercial de milho.

Tabela 7. Valores médios de altura de plantas (AP), altura de inserção da espiga superior (AIE), índice de clorofila Falker total (ICF), número de fileiras por espiga (NFE), porcentagem de acamamento (ACA) das plantas e peso de 1000 grãos (P1000) em função das variedades de milho. Araras/SP e Muzambinho/MG, ano agrícola 2014/15.

\begin{tabular}{lccc}
\hline \multicolumn{1}{c}{ Variedades } & AP $(\mathrm{cm})$ & AIE $(\mathrm{cm})$ & ICF \\
\hline AL Avaré & $243,88 \mathrm{bc}$ & $133,95 \mathrm{~cd}$ & $56,34 \mathrm{a}$ \\
AL Bandeirante & $232,66 \mathrm{c}$ & $129,44 \mathrm{~d}$ & $55,15 \mathrm{ab}$ \\
Cativerde 02 & $252,53 \mathrm{bc}$ & $154,01 \mathrm{bc}$ & $55,85 \mathrm{a}$ \\
AL Piratininga & $266,98 \mathrm{~b}$ & $157,44 \mathrm{~b}$ & $56,52 \mathrm{a}$ \\
Santa Rita 1 & $339,11 \mathrm{a}$ & $233,53 \mathrm{a}$ & $52,13 \mathrm{~b}$ \\
Santa Rita 2 & $343,55 \mathrm{a}$ & $232,36 \mathrm{a}$ & $53,53 \mathrm{ab}$ \\
UFVM - 200 Soberano & $253,06 \mathrm{bc}$ & $147,11 \mathrm{bcd}$ & $56,16 \mathrm{a}$ \\
\hline & NFE & ACA $(\%)$ & P1000 $(\mathrm{g})$ \\
\hline AL Avaré & $14,13 \mathrm{a}$ & $17,63 \mathrm{e}$ & $329,41 \mathrm{ab}$ \\
AL Bandeirante & $14,33 \mathrm{a}$ & $27,13 \mathrm{bc}$ & $339,27 \mathrm{ab}$ \\
Cativerde 02 & $14,20 \mathrm{a}$ & $18,63 \mathrm{de}$ & $315,30 \mathrm{ab}$ \\
AL Piratininga & $14,01 \mathrm{a}$ & $18,63 \mathrm{de}$ & $344,15 \mathrm{a}$ \\
Santa Rita 1 & $12,75 \mathrm{bc}$ & $32,75 \mathrm{ab}$ & $339,91 \mathrm{a}$ \\
Santa Rita 2 & $11,78 \mathrm{c}$ & $35,13 \mathrm{a}$ & $346,58 \mathrm{a}$ \\
UFVM - 200 Soberano & $13,90 \mathrm{ab}$ & $25,13 \mathrm{~cd}$ & $302,34 \mathrm{~b}$ \\
\hline
\end{tabular}

Médias seguidas de mesma letra na coluna não diferem entre si de acordo com o teste de Tukey $(\mathrm{p}<0,05)$.

No que diz respeito ao ICF, as variedades AL Avaré, Cativerde 02, AL Piratininga e UFVM - 200 Soberano apresentaram valores superiores que, no entanto, não diferenciaram dos obtidos nas variedades AL Bandeirante e Santa Rita 2 (Tabela 7). Com exceção das variedades Santa Rita 1 e 2, as demais apresentaram ICF adequado para o estádio R1 de desenvolvimento do milho, considerado como mínimo de 55 para esse estádio de

Cultura Agronômica, Ilha Solteira, v.26, n.3, p.417-432, 2017 
desenvolvimento (MALAVOLTA et al., 1997). Alguns autores apontam uma relação positiva entre a leitura do clorofilômetro e o teor de $\mathrm{N}$ foliar, uma vez que o $\mathrm{N}$ é um dos constituintes da molécula de clorofila (COSTA et al., 2012; VARGAS et al., 2012; VALDERRAMA et $a l .$, 2014), o que não se verificou nesse trabalho, uma vez que não houve diferença estatística entre os locais avaliados para o parâmetro ICF, apenas para o parâmetro teor de $\mathrm{N}$ foliar (Tabela 6).

Uma relação positiva entre o ICF e a produtividade do milho também foi evidenciada por alguns autores (COSTA et al., 2012; HURTADO et al., 2009), corroborando com os resultados obtidos nesse trabalho para a variedade Santa Rita 1, que apresentou o menor ICF (Tabela 7) e também de produtividade dos grãos (Tabela 5).

Para o NFE, os menores valores foram observados nas variedades Santa Rita 2 e Santa Rita 1 que, por sua vez, não diferiu da variedade UFVM - 200 Soberano, que apresentou valor semelhante aos valores das demais variedades (Tabela 7). Segundo Gitti et al. (2012), o NFE é determinado pelo genótipo e não pelo ambiente, enquanto o NGF e o NGE, por sua vez, são mais afetados pelas condições ambientais.

Em relação à porcentagem de plantas acamadas (ACA), a variedade Santa Rita 2 apresentou o valor mais elevado, semelhante ao da variedade Santa Rita 1 que, por sua vez, não diferiu da variedade AL Bandeirante. Já a variedade AL Avaré apresentou menor porcentagem de acamamento, estatisticamente semelhante aos percentuais observados nas variedades Cativerde 02 e AL Piratininga (Tabela 7). O acamamento poder ser consequência da altura elevada das plantas (DUETE et al., 2008) e pode ser influenciado também pela altura de inserção das espigas e diâmetro dos colmos (FOLONI et al., 2008). No entanto, ressaltase que a variedade AL Bandeirante, com menor AP e AIE em comparação às demais, apresentou porcentagem de acamamento superior a outras variedades com maior AP e AIES, como a AL Avaré e AL Piratininga (Tabela 7). Salienta-se que o acamamento de plantas se mostra bastante complexo, podendo ser reflexo de fatores genéticos inter-relacionados à fatores climáticos (principalmente chuvas e ventos), do solo, práticas culturais inadequadas e prejuízos pelos ataques de pragas e doenças (GOMES et al., 2010). Não foi possível determinar, nesse estudo, quais desses fatores contribuíram para essa porcentagem de acamamento mais elevada na variedade AL Bandeirante, mas tal situação não incidiu na redução da produtividade da variedade, conforme pode ser observado na Tabela 5.

Em relação ao peso de 1000 grãos (P1000), o menor valor foi observado para a variedade UFVM - 200 Soberano, estatisticamente semelhante ao obtido pelas variedades AL Avaré, Cativerde 02 e AL Bandeirante que, por sua vez, não diferiram dos valores das variedades AL Piratininga, Santa Rita 1 e Santa Rita 2 (Tabela 7). A redução do peso de 1000 grãos observado para a variedade UFVM - 200 Soberano pode ter afetado a produtividade desta variedade em Muzambinho, apesar do número de grãos por espiga, para essa variedade, não ter se diferenciado das demais, nesse município. Para a variedade Cativerde 02 , o menor P1000 pode ter sido compensado, em parte, por um elevado número de grãos por espiga, uma vez que essa variedade não apresentou baixa produtividade de grãos. Já para a variedade Santa

Cultura Agronômica, Ilha Solteira, v.26, n.3, p.417-432, 2017 
Rita 2, o maior peso de 1000 grãos não resultou no aumento da produtividade da variedade em Araras (Tabela 5).

\section{CONCLUSÃO}

1. O ambiente, principalmente os efeitos da altitude e a distribuição da precipitação pluviométrica, mostrou-se o fator mais importante para o rendimento de grãos de milho quando em manejo orgânico. O desempenho agronômico de todas as variedades foi superior quando cultivadas em maior altitude.

2. Nas condições do experimento, a variedade AL Piratininga apresentou bom desempenho agronômico tanto em alta quanto em baixa altitude.

3. Nas condições experimentais, as variedades crioulas apresentaram desempenho agronômico semelhante ao das variedades comerciais nos dois locais avaliados, indicando que as mesmas podem ser utilizadas em plantios comerciais sob manejo orgânico.

\section{REFERÊNCIAS BIBLIOGRÁFICAS}

ARAUJO, A. V.; BRANDÃO JUNIOR, D. S.; FERREIRA, I. C. P. V.; COSTA, C. A.; PORTO, B. B. A. Desempenho agronômico de variedades crioulas e híbridos de milho cultivados em diferentes sistemas de manejo. Revista Ciência Agronômica, Fortaleza, v. 44, n. 4, p.885-892, 2013.

ARAÚJO JUNIOR, B. B.; MELO, A. E.; MATIAS, J. N. R.; FONTES, M. A. Avaliação de variedades crioulas de milho para produção orgânica no semiárido potiguar. Holos, Natal, ano 31, v. 3, p.102-108, 2015.

ARGENTA, G.; SANGOI, L.; SILVA, P. R. F.; RAMPAZZO, C.; GRACIETTI, L. C.; STIEDER, M. L.; FORSTHOFER, E. L.; SUHRE, E. Potencial de rendimento de grãos de milho em dois ambientes e cinco sistemas de produção. Scientia Agraria, Curitiba, v. 4, n. 1-2, p.27-34, 2003.

BALBINOT JÙNIOR, A. A.; BACKES, R. L.; ALVES, A. C.; OGLIARI, J. B.; FONSECA, J. A. Contribuição de componentes de rendimento na produtividade de grãos em variedades de polinização aberta de milho. Revista Brasileira de Agrociência, Pelotas, v. 11, n. 2, p.161-166, 2005.

BRACHTVOGEL, E. L.; PEREIRA, F. R. S.; CRUZ, S. C. S.; BICUDO, S. J. Densidades populacionais de milho em arranjos espaciais convencional e equidistante entre plantas. Ciência Rural, Santa Maria, v. 39, n. 8, p.2334-2339, 2009.

CARPENTIERI-PÍPOLO, V.; SOUZA, A.; SILVA, D. A.; BARRETO, T. P.; GARBUGLIO, D. D.; FERREIRA, J. M. Avaliação de cultivares de milho crioulo em sistema de baixo nível tecnológico. Acta Scentiarum. Agronomy, Maringá, v. 32, n. 2, p.229-232, 2010.

Cultura Agronômica, Ilha Solteira, v.26, n.3, p.417-432, 2017 
CLAESSEN, M. E. C. (Org). Manual de métodos de análise de solo. 2. ed. Rio de Janeiro: EMBRAPA- CNPS, 1997. 212 p. (Documentos, 1).

COELHO, A. M. Nutrição e adubação do milho. Sete Lagoas: Embrapa Milho e Sorgo, 2006. 10 p. (Circular Técnica, 78).

COELHO, A. M.; FRANÇA, G. E.; PITTA, G. V. E.; ALVES, V. M. C.; HERNANI, L. C. Nutrição e adubação do milho. In: CRUZ, J. C. (Ed. Técnico). Cultivo do Milho. 6. ed. Sete Lagoas: Embrapa Milho e Sorgo, 2010. (Sistema de Produção, 1 - versão eletrônica). Disponível em: http://www.cnpms.embrapa.br/publicacoes/milho_6_ed/feraduba.htm. Acesso em: 20 set. 2016.

COSTA, A. S. V.; GALVÃO, E. R.; SILVA, M. B.; PREZOTTI, L.; RIBEIRO, J. M. O. Densidades populacionais de milho na região do Vale do Rio Doce. Revista Ceres, Viçosa, v. 52, n. 299, p.33-34, 2005.

COSTA, N. R.; ANDREOTTI, M.; GAMEIRO, R. A.; PARIZ, C. M.; BUZETTI, S.; LOPES, K. S. M. Adubação nitrogenada no consórcio de milho com duas espécies de braquiária em sistema de plantio direto. Pesquisa Agropecuária Brasileira, Brasília, v. 47, n. 8, p.10381047, 2012.

CRUZ, J. C.; PEREIRA FILHO, I. A.; OliVEIRA, A. C.; GUIMARÃES, L. J. M.; QUEIROZ, L. R.; MATRANGOLO, W. J. R.; MOREIRA, J. A. A. Produtividade de variedades de milho em sistema orgânico de produção. Sete Lagoas: Embrapa Milho e Sorgo, 2009. 6 p. (Comunicado Técnico, 171).

CRUZ, J. C.; PEREIRA FILHO, I. A.; SIMÃO, E. P. 478 cultivares de milho estão disponíveis no mercado de sementes do Brasil para a safra 2014/15. Sete Lagoas: Embrapa Milho e Sorgo, 2014. 35 p. (Documentos, 167).

DUETE, R. R. C.; MURAOKA, T.; SILVA, E. C.; TRIVELIN, P. C. O.; AMBROSANO, E. J. Manejo da adubação nitrogenada e utilização do nitrogênio $\left({ }^{15} \mathrm{~N}\right)$ pelo milho em Latossolo Vermelho. Revista Brasileira de Ciência do Solo, Viçosa, v. 32, n. 1, p.161-171, 2008.

EMPRESA BRASILEIRA DE PESQUISA AGROPECUÁRIA - EMBRAPA. Sistema Brasileiro de Classificação de Solos. 3. ed. Brasília: Embrapa, 2013. 353 p.

FANCELLI, A. L. Ecofisiologia, fenologia e implicações básicas de manejo. In: GALVÃO, J. C. C.; BORÉM, A., PIMENTEL, M. A. (Ed.). Milho: do plantio à colheita. Viçosa: Editora UFV, 2015. cap. 3 , p.50-76.

FALKER, AUTOMAÇÃO AGRÍCOLA. Manual do medidor eletrônico de teor clorofila (ClorofiLOG/CFL 1030). Porto Alegre: Falker, 2008. 33 p.

FERREIRA, D. F. Sisvar: a computer statistical analysis system. Ciência e Agrotecnologia, Lavras, v. 35, n. 6, p.1039-1042, 2011. 
FOLONI, J. S. S.; SANTOS, D. H.; BRIANCINI, R. Competição de cultivares de milho em espaçamento reduzido no ambiente safrinha do oeste paulista. Colloquium Agrariae, Presidente Prudente, v. 4, n. 2, p.01-08, 2008.

FONSECA, D. J.; PARIZOTTO, C.; MERGENER, R. A. Cultivo agroecológico de cinco variedades de polinização aberta de milho no município de Campos Novos, SC. Unoesc \& Ciência, Joaçaba, v. 6, n. 1, p.19-24, 2015.

FORSTHOFER, E. L.; SILVA, P. R. F.; STRIEDER, M. L.; MINETTO, T.; RAMBO, L.; ARGENTA, G.; SANGOI, L.; SUHRE, E.; SILVA, A. A. Desempenho agronômico e econômico do milho em diferentes níveis de manejo e época de semeadura. Pesquisa Agropecuária Brasileira, Brasília, v. 41, n. 3, p.399-407, 2006.

FREITAS, R. S.; PEREIRA, A. D.; LEÃO, P. C. L.; TICELLI, M.; KASAI, F.; SAWAZAKI, E.; CAZENTINI-FILHO, G.; MARTINS, A L. M.; BORGES, W. L. B.; STRADA, W. L.; FINOTO, E. L.; OLIVEIRA, A. L.; VITOR, L. G.; TOKUDA, F. S.; PONTE, M. S. Desempenho de cultivares de milho convencionais na região norte/oeste do estado de São Paulo nas safras 2011/12 e 2012/13. Revista Núcleos, Ituverava, edição especial, p.117-124, 2013.

GALON, L.; TIRONI, S. P.; ROCHA, A. A.; SOARES, E. R.; CONCENÇO, G.; ALBERTO, C. M. Influência dos fatores abióticos na produtividade da cultura do milho. Revista Trópica - Ciências Agrárias e Biológicas, Chapadinha, v. 4, n. 3, p.18-38, 2010.

GITTI, D. C.; ARF, O.; VILELA, R. G.; PORTUGAL, J. R.; KANEKO, F. H.; RODRIGUES, R. A. F. Épocas de semeadura de crotalária em consórcio com milho. Revista Brasileira de Milho e Sorgo, Sete Lagoas, v. 11, n. 2, p.156-168, 2012.

GOMES, L. S.; BRANDÃO, A. M.; BRITO, C. H.; MORAES, D. F.; LOPES, M. T. G. Resistência ao acamamento de plantas e ao quebramento do colmo em milho tropical. Pesquisa Agropecuária Brasileira, Brasília, v. 45, n. 2, p.140-145, 2010.

GUimarÃes, L. J. M.; PACHECO, C. A. P.; GUIMARÃES, P. E. O.; MEIRELLES, W. F.; PARENTONI, S. N.; SILVA, A. R.; COSTA, R. V.; CASELA, C. R.; CRUZ, J. C.; MACHADO, A. T.; SOUZA, F. R. S.; CECCON, G.; SOUZA, E. D.; ARCE, H.; MUNIZ, J. A.; GERAGE, A. C.; ARAÚJO, P. M.; VALENTINI, L.; DENUCCI, S; GODINHO, V. P. C. Comportamento de variedades de milho em diversas regiões do Brasil: ano agrícola 2007/08. Sete Lagoas: Embrapa Milho e Sorgo, 2009. 15 p. (Comunicado Técnico, 168).

HURTADO, S. M. C.; RESENDE, A. V.; SILVA, C. A.; CORAZZA, E. J.; SHIRATSUCHI, L. S. Variação espacial da resposta do milho à adubação nitrogenada de cobertura em lavoura no Cerrado. Pesquisa Agropecuária Brasileira, Brasília, v. 44, n. 3, p.300-309, 2009.

KAPPES, C.; CARVALHO, M. A. C.; YAMASHITA, O. M.; SILVA, J. A. N. Influência do nitrogênio no desempenho produtivo do milho cultivado na segunda safra em sucessão à soja. Pesquisa Agropecuária Tropical, Goiânia, v. 39, n. 3, p.251-259, 2009.

Cultura Agronômica, Ilha Solteira, v.26, n.3, p.417-432, 2017 
KÖPPEN, W. Climatologia: con um estúdio de los climas de la Tierra. México: Fondo de Cultura Economica, 1948. 478 p.

MALAVOLTA, E.; VITTI, G. C.; OLIVEIRA, S. A. Avaliação do estado nutricional das plantas: princípios e aplicações. 2. ed. Piracicaba: Associação Brasileira para Pesquisa da Potassa e do Fosfato, 1997. 319 p.

MAGAlHÃES, P. C.; SOUZA, T. C. Cultivo do milho. Sete Lagoas: Embrapa Milho e Sorgo, 2011. (Sistema de Produção, 1 - versão eletrônica). Disponível em: http://www.cnpms.embrapa.br/publicacoes/milho_8_ed/ecofisiologia.htm. Acesso em: 20 set. 2016.

NASCIMENTO, F. M.; BICUDO, S. J.; FERNANDES, M.; RODRIGUES, J. G. L.; FERNANDES, J. C. Diagnose foliar em plantas de milho em sistema de semeadura direta em função de doses e épocas de aplicação de nitrogênio. Pesquisa Aplicada \& Agrotecnologia, Guarapuava, v. 5, n. 1, p.67-75, 2012.

ROLIM, G. S.; SENTELHAS, P. C.; BARBIERI, V. Planilhas no ambiente EXCEL ${ }^{\mathrm{TM}}$ para os cálculos de balanços hídricos: normal, sequencial, de cultura e de produtividade real e potencial. Revista Brasileira de Agrometeorologia, Sete Lagoas, v. 6, n. 1, p.133-137, 1998.

SANTOS, N. C. B.; CARMO, S. A.; MATEUS, G. P.; KOMURO, L. K.; PEREIRA, L. B.; SOUZA, L. C. D. Características agronômicas e de desempenho produtivo de cultivares de milho-verde em sistema orgânico e convencional. Semina: Ciências Agrárias, Londrina, v. 36, n. 3, suplemento 1, p.1807-1822, 2015.

SILVEIRA, D. C.; BONETTI, L. P.; TRAGNAGO, J. L.; MONTEIRO, V. Caracterização agromorfológica de variedades de milho crioulo (Zea mays L.) na região noroeste do Rio Grande do Sul. Ciência e Tecnologia, Cruz Alta, v. 1, n. 1, p.01-11, 2015.

VALDERRAMA, M.; BUZETTI, S.; TEIXEIRA FILHO, M. C. M.; BENETT, C. G. S.; ANDREOTTI, M. Adubação nitrogenada na cultura do milho com ureia revestida por diferentes fontes de polímeros. Semina: Ciências Agrárias, Londrina, v. 35, n. 2, p.659-670, 2014.

VARGAS, V. P.; SANGOI, L.; ERNANI, P. R.; SIEGA, E.; CARNIEL, G.; FERREIRA, M. A. Os atributos nas folhas são mais eficientes que o $\mathrm{N}$ mineral no solo para avaliar a disponibilidade desse nutriente para o milho. Bragantia, Campinas, v. 71, n. 2, p.245-255, 2012. 